\title{
Memórias da Escola Superior de Educação Física da Universidade Federal do Rio Grande do Sul (ESEF/UFRGS): um estudo do período de sua fundação até a federalização (1940-1969)
}

Janice Zarpellon Mazo*

Resumo: A Escola de Educação Física - ESEF/UFRGS foi a primeira instituição formadora de professores de Educação Física fundada no Estado do Rio Grande do Sul no Estado Novo (1937-1945). O estudo tem por objetivo reconstituir a memória da ESEF/UFRGS, desde sua fundação até a sua federalização (1940-1969), buscando identificar os primeiros professores, alunos e funcionários e registrar as condições dos equipamentos e das instalações onde eram realizadas as aulas. Para tanto, foram consultados documentos institucionais, revistas e jornais, como também, foram coletados depoimentos orais de ex-professores e alunos. As ações políticas, culturais e educacionais desencadeadas no Estado Novo favoreceram a fundação da ESEF/UFRGS em 1940. Enquanto a ESEF/UFRGS esteve sob a tutela do Estado do Rio Grande do Sul (até 1969), suas condições de funcionamento eram restritas, principalmente pelo fato de que as atividades acadêmicas não eram realizadas em instalações próprias.

Palavras-chave: memória, ESEF/UFRGS, fundação, administração estadual.

\section{Introdução}

A Escola de Educação Física da Universidade Federal do Rio Grande do Sul (ESEF/UFRGS) está comemorando neste ano de 2005 seu aniversário de 65 anos. A ESEF/UFRGS foi a primeira instituição formadora de professores de Educação Física implantada no Estado, além de ser considerada uma das primeiras escolas de Educação Física fundada no país para atender a formação de professores civis (DACOSTA, 1971). . Durante 30 anos, período em que este-

* Doutora em Ciências do Desporto. Professora da Escola de Educação Física/UFRGS

1 No início da década de 70 foram fundadas no Estado do Rio Grande do Sul várias instituições de ensino superior em Educação Física: Centro de Educação Física e Desportos da Universidade Federal de Santa Maria (1970) em Santa Maria; Escola

Movimento, Porto Alegre, v. 11, n. 1, p.143-167, janeiro/abril de 2005 
ve sob a tutela do Estado, a ESEF/UFRGS permaneceu como a única instituição de ensino superior em Educação Física no Estado do Rio Grande do Sul (GUTIERREZ, 1976).

Embora a ESEF/UFRGS já tenha percorrido um longo caminho, há carência de estudos que reconstituam sua memória. Inclusive, na obra organizada por Guedes e Sanguinetti (1994), que se propôs a resgatar a memória histórica da UFRGS, não se encontra professores, alunos ou técnico-administrativos da ESEF/UFRGS entre os autores convidados. Assim, curiosamente, a ESEF/UFRGS não foi lembrada, apesar de ter sido incorporada à UFRGS em 1969. Todavia, na obra comemorativa dos 70 anos da UFRGS, Pesavento (2004) mencionou que a ESEF/UFRGS entrou em funcionamento a partir de 1940, como instituição estadual e sua integração à Universidade Federal do Rio Grande do Sul ocorreu em 1969.

Considerando que as demais faculdades de Educação Física surgiram somente 30 anos depois, segundo Gutierrez (1976), a ESEF/UFRGS tornou-se uma referência para as demais instituições na formação profissional no campo da Educação Física, Esporte, Lazer e Dança. O ex-aluno da ESEF/UFRGS, vereador Carlos Garcia, em seu depoimento reafirma esta idéia: "A excelência do curso de Educação Física, aliada à qualificação dos professores, permitiu-me adquirir grandes conhecimentos e a chance de tornar-me um profissional capaz" (OLIVEIRA \& LICHT, 2004, p. 189). Ao recuperar fragmentos da memória da fase em que esteve sob a tutela do Estado do Rio Grande do Sul (1940-1969) ${ }^{3}$ espera-se

Superior de Educação Física da Fundação Educacional do Vale do Jacuí (1970) em Cachoeira do Sul; Escola Superior de Educação Física de Santa Cruz do Sul (1970) em Santa Cruz do Sul; Instituto Porto Alegre - IPA (1971) em Porto Alegre; Escola Superior de Educação Física da Fundação Universidade de Passo Fundo (1971) em Passo Fundo; Faculdade de Educacão Física da Associação de Professores de Cruz Alta - APROCRUZ (1973) em Cruz Alta; Faculdade de Educação Física da Fundação Àtila Taborda - FUNBA (1973) em Bagé; Escola de Educação Física da FEEVÁLE (1973) Federal de Pelotas (1973) em Pelotas (MAZO, 1997).

2 Por exemplo, entre os professores pioneiros do Curso de Licenciatura em Educação Física da Universidade Federal de Santa Maria, havia alunos egressos da ESEF/UFRGS: Cecy Funck Rubin, Haimo Hartmuth Fensteiseifer, Heloísa Pfeifer de Vasconcellos, Pedro Luiz Beno Lang, Jefferson Thadeu Canfield, Ruy Jornada Krebs e Floriano Dutra Monteiro (MAZO, 1993).

3 A ESEF foi autorizada a funcionar oficialmente pelo Decreto-Lei n. 7.219 de 27/5/ 1941 assinado pelo presidente Getúlio Vargas. O Regulamento da ESEF foi aprovado em 13/12/1943 pela Portaria n. 275-D e pelo Decreto-Lei n. 394 de 13/12/1943. O reconhecimento dos diversos cursos oferecidos pela ESEF foi obtido através do Decreto-Lei n. 15.582 de 16/5/1944. A Escola foi federalizada em 21/10/1969 pelo Decreto-Lei n. 997, mas a passagem definitiva do âmbito estadual para o federal ocorreu em 16/9/1970 (NEGRINI, 1996).

Movimento, Porto Alegre, v. 11, n. 1, p.143-167, janeiro/abril de 2005 
contribuir para o dimensionamento do papel desta instituição no desenvolvimento da Educação Física e do esporte no âmbito local, regional e nacional.

Este estudo se divide em duas partes. Na primeira realiza-se a contextualização das ações políticas, culturais e educacionais que favoreceram a implantação da ESEF/UFRGS. O objetivo é apresentar o cenário social que desencadeou a valorização da Educação Física e dos esportes no país. Na segunda parte, visando atingir o objetivo central de reconstituir a memória do período em que a ESEF/UFRGS era uma instituição estadual, busca-se identificar os primeiros professores, alunos e funcionários que ajudaram a construir os alicerces da instituição; relacionar as disciplinas oferecidas nos primeiros cursos da ESEF/UFRGS; registrar as condições da instalações e equipamentos onde eram realizadas as aulas; além de listar a participação dos professores e alunos da ESEF/UFRGS em eventos acadêmicos, cívicos e esportivos. Para reconstituir os primeiros 30 anos de existência desta instituição foram consultados documentos institucionais (atas, cadernos de chamadas, relatórios), revistas, jornais e obras comemorativas; além disto, foram coletados depoimentos orais de ex-professores e ex-alunos, que participaram efetivamente deste processo.

Em razão de o estudo estar delimitado ao período em que a ESEF/UFRGS ainda não havia sido incorporada pela Universidade Federal do Rio Grande do Sul, será utilizada apenas a sigla ESEF para identificá-la no decorrer do texto.

\section{As ações políticas, culturais e educacionais no Estado Novo}

No Estado Novo (1937-1945) foi desencadeada a campanha de nacionalização caracterizada pelo intercruzamento de ações políticas, culturais e educacionais. Este processo era perpassado pelo trinômio Estado, Cultura e Educação (LEVINE, 1980). O projeto nacionalista buscava a homogeneização cultural, sendo contrário a qualquer manifestação pluralista e diversificada.

No período acentuou-se a preocupação com a formação da identidade cultural brasileira, pois como referiu Ortiz (1994), o Brasil não tinha uma identidade e, portanto, não tinha uma nação. Não havia uma imagem de povo brasileiro, mas sim, um Estado composto de governo e território. Frente a esta situação, o Estado brasileiro assumiu características intervencionistas, enquanto promotor de políticas culturais e educacionais destinadas a construir a nação brasileira.

Movimento, Porto Alegre, v. 11, n. 1, p.143-167, janeiro/abril de 2005 
A educação tornou-se uma questão fundamental para a qualificação do trabalhador e homogeneização cultural do país. O Ministério da Educação e Saúde Pública (MES) implantou uma ação estruturada das políticas educacionais, padronizando o sistema educacional, imprimindo um conteúdo nacional a ser ministrado nas escolas e eliminando os conteúdos regionais que fortaleciam as minorias étnicas, lingüísticas e culturais. Conforme Schwartzman; Bomeny e Costa (1984, p. 141- 42), “a construção da nacionalidade deveria ser a culminação de toda ação pedagógica do ministério". As propostas de educação nacional e as novas leis migratórias implementadas pelo governo reforçaram a nacionalização do país.

O presidente Getúlio Vargas proclamava a necessidade de medidas voltadas "a instrução, educação, higiene, alimentação, habitação; a proteção às mulheres, às crianças, à invalidez e à velhice; o crédito, o salário e, até, o recreio, como os desportos e cultura artística" (WASSERMAN, 1998, p. 245). Uma atenção especial do governo foi dada às políticas educacionais. Foi elaborado o Plano Nacional de Educação, que determinou a estrutura básica do ensino primário e secundário, além da estruturação do ensino industrial, comercial, agrícola e normal pelo ministro Gustavo Capanema (CARONE, 1976).

A Reforma Capanema do ensino visava à organização da estrutura escolar do país e, através da educação, extinguir as diferenças culturais entre as regiões brasileiras. De acordo com Fiori (1995), seu plano educacional centrava-se em dois aspectos: formação de mão-de-obra industrial e formação cívica. A formação cívica preconizada pelo plano nacional de educação buscava difundir a idéia de uma identidade cultural brasileira, que seria veiculada por várias disciplinas, entre elas a Educação Física. As atividades de Educação Física passam a ser valorizadas na escola, visando inculcar parâmetros identitários mínimos para a formação de uma identidade cultural brasileira, além de atuar para o fortalecimento da mão-de-obra colaborando para a consolidação do Estado Brasileiro. (BERCITO, 1996; BETTI, 1991).

As iniciativas governamentais no âmbito da Educação Física e dos esportes, segundo Castellani Filho (1988) multiplicaram-se, visando seu alinhamento com as transformações profundas da sociedade brasileira. A constituição brasileira de 1937 estabeleceu a obrigatoriedade da Educação Física em todas as escolas primárias, normais e secundárias do país (Artigo 131). Ao Estado foi atribuída a responsabilidade de assegurar as condições físicas e mo-

Movimento, Porto Alegre, v. 11, n. 1, p.143-167, janeiro/abril de 2005 
rais da infância e da juventude (Artigo 127), e o auxílio e proteção das associações destinadas ao adestramento e a sua projeção no futuro do indivíduo e da nação (Artigo 132).

As aulas de Educação Física passaram a integrar o corpo de disciplinas do ensino primário, ginasial e normal. ${ }^{4}$ As escolas normais de primeiro e segundo ciclo, destinadas, respectivamente, à formação de regentes de ensino e professores primários contemplavam, além da Educação Física, as disciplinas práticas de trabalhos manuais, Desenho e Canto Orfeônico (AVANCINI, 2000). Em detrimento das disciplinas teóricas, como por exemplo, a Didática, a Psicologia e a Sociologia eram oferecidas às disciplinas práticas em todas as séries dos cursos. A valorização da Educação Física foi evidenciada nas palavras do presidente Getúlio Vargas:

Agora que a Educação Physica está na ordem do dia, nos programmas officiaes e nas associaçóes particulares, na casa do rico e na casa do pobre; agora que, felizmente, nos convencemos da necessidade de educar, fortalecer e desenvolvero physico dos brasileiros, por meio da gymnastica; agora que o enthusiasmo se apoderou de professores e alumnos pela arte que fez a grandeza da Grécia (ANTUNES, 01/01/1937, p. 5).

Para atender as novas exigências, o ministro da educação Gustavo Capanema reorganizou o Ministério da Educação e Saúde e criou a Divisão de Educação Física (DEF), através da Lei n 378 de 13/3/1937, setor subordinado ao Departamento Nacional de Educação (FERREIRA NETO, 1999). A Divisão de Educação Física foi uma iniciativa governamental, visando à organização e o controle da educação física no país. Faria Jr. $(1987$, p. 16) referiu que a implantação do DEF foi "uma ação estratégica vinculada ao processo de evolução, no sentido da criação do Estado Novo, cujos ideólogos viam na Educação Física um auxiliar poderoso para o fortalecimento do estado e um poderoso meio para o aperfeiçoamento da raça, um dos pontos de seu ideário".

4 No Rio Grande do Sul, em 1882, já era mencionada a necessidade de torna obrigatória a prática de exercícios físicos na escola primária (LIMA, 1909, p. 21). Passados alguns anos, em 1890, ocorreu a regulamentação da instrução primária e secundária realizada no país por Benjamin Constant, a qual determinou que as e secundária realizada no pais por Benjamin Constant, a qual determinou que as escolas devessem ter, além de salas de aula, biblioteca e museu, um ginásio para exercícios físicos e um pórtico de madeira para a realização dos exercícios ginásticos. Em Porto Alegre, o programa escolar previa calistenia, evoluções militares além da ginástica alemã. A obrigatoriedade da Educação Física no Estado do Rio Grande do Sul, do ensino primário até o normal foi determinada pelo Decreto-Le n. 8.063 de 10/10/1945, no artigo 100 - "A educação física, o ensino cívico e o de trabalhos manuais serão obrigatórios em tôdas as escolas primárias, normais e secundárias" (Rio Grande do Sul, 1990, p. 139).

Movimento, Porto Alegre, v. 11, n. 1, p.143-167, janeiro/abril de 2005 
Um dos principais problemas encontrados pelo DEF era a carência de profissionais habilitados para suprir as necessidades do ensino da Educação Física. A maioria dos profissionais especializados era oriunda do meio militar, pois não havia escolas que formassem professores civis. Neste contexto, através do Decreto n. 1.212 de 1939, começou a ser exigida formação profissional específica para professor de Educação Física, técnico esportivo e médico especializado em Educação Física e esportes. No mesmo ano foi fundada a Escola Nacional de Educação Física no Rio de Janeiro, a primeira instituição no país voltada para a formação de professores civis (MELO, 1996).

Tornou-se imperiosa a formação de "pessoal técnico de forma a poder ministrar a indispensável instrução sem os graves inconvenientes oriundos da falta de conhecimentos especializados" (Revista do Globo, 1946, p. 35). A importância atribuída aos benefícios da Educação Física e do esporte cresceu com a necessidade de "assistência de técnicos especializados". Entretanto, não havia professores de Educação Física suficientes para atender as escolas e as novas demandas das associações esportivas. Conforme Piccoli (1994), a Educação Física era desenvolvida com limitações na escola, em função de alguns fatores, entre eles, a inexistência de uma instituição profissional que formasse o professor.

Para tentar amenizar o problema da escassez de professores habilitados, o governo do Estado do Rio Grande do Sul, que tinha à frente o interventor federal general Osvaldo Cordeiro de Farias, promoveu o aprimoramento dos professores através da realização de cursos. Foram realizados 15 cursos de aperfeiçoamento para diretores e orientadores de ensino, professores de música, de desenho e de Educação Física no período de 1939 a 1942 (PICCOLI, 1994). Nestes cursos intensivos, os professores recebiam instruções para desenvolver as atividades cívicas nas aulas de canto, poesia e Educação Física. A Educação Física deveria desenvolver a marcha e os jogos, além da preparação das festividades cívicas.

Além dos cursos temporários para suprir a necessidade emergencial de professores, o secretário de educação do Estado, médico José Pedro Coelho de Souza, apresentou o projeto para a criação do Departamento de Educação Física do Estado do Rio Grande do Sul (DEEF) em 1939. O DEEF era um órgão técnico, subordinado à Secretaria de Educação do Estado, que tinha como atribuição dirigir, orientar e fiscalizar a prática da Educação Física nos estabelecimentos de ensino, oficiais e particulares, nos institutos de ginástica e nas associações esportivas, além de formar

Movimento, Porto Alegre, v. 11, n. 1, p.143-167, janeiro/abril de 2005 
pessoal técnico em Educação Física e esportes. De acordo com Franco; Silva e Schidrowitz (1940, p. 637-639) eram atribuições do DEEF:

I- Dirigir e orientar a prática da educação física no Estado;

II- Organizar a prática da ginástica nas instituições públicas onde se torne necessária ou aconselhável;

III- Realizar pesquisas sobre a educação física e os desportos, indicando os métodos mais adequados à sua prática no estado;

IV- Organizar e fazer adotar, como padrão geral, um plano sistemático de educação física;

$V$ - Estabelecer e dirigir campos de recreio e jogos de colônias de férias;

VI- Fiscalizar a prática de desportos, especialmente competições, torneios, exibições e reuniões em que se cobrem ingressos

VII- Organizar e patrocinar provas de ginástica, desportos e concursos de eficiência física;

VIII- Promover a fundação de organizações ou agremiações de caráter particular que visem a educação física, especialmente da criança e prestar-lhes colaboração; IX-Incentivar a educação física feminina;

$X$-Habilitar candidatos a instrutores ou professores de educação física;

XI-Proceder ao registro anual das agremiações de ginástica, associações desportivas e de quaisquer outras organizações de educação física;

XII-Difundir, demodo geral, conhecimentos relativos à educaçãofísica eaodesporto.

O capitão Olavo Amaro da Silveira, primeiro diretor do DEEF, em seu discurso justifica as ações do governo estadual no âmbito da Educação Física:

Com o incontestável valor da educação física na formação de uma nação forte, os govêrnos, indiferentemente de suas formas, foram obrigados a olhar com carinhoe a legislarcuidadosamentepara êste setor da educação. OChefe do Govêrno Rio Grandense nãopoderia ficarindiferente ao grandemovimentonacional que tem tido, nestaúltima década, a educação física (FRANCO; SILVA e SCHIDROWITZ, 1940, p. 637).

Na perspectiva de executar a nova política de promoção do desenvolvimento da Educação Física nacional, suprindo a necessidade de profissionais especializados em Educação Física e esportes, o DEEF implantou a primeira instituição formadora de profissionais no Estado do Rio Grande do Sul, a Escola Superior de Educação Física (ESEF) em 1940 (SILVEIRA, 1943). Quando a ESEF foi fundada já existia a Universidade de Porto Alegre (UPA), instituição de ensino superior mantida pelo Estado do Rio Grande do Sul, mas, curiosamente, a Escola não foi incorporada pela Universidade.'

5 A constituição do Estado do Rio Grande do Sul de 1947 alterou o nome da Universidade de Porto Alegre (UPA) para Universidade do Rio Grande do Sul (URGS) (PESAVENTO, 2004, p. 60)

Movimento, Porto Alegre, v. 11, n. 1, p.143-167, janeiro/abril de 2005 


\section{Notas acerca da Fundação da Escola Superior de Educação Física (ESEF)}

A fundação da ESEF ocorreu no ano de 1940, sendo nomeado seu primeiro diretor, o capitão da Brigada Militar Olavo Amaro da Silveira, ${ }^{6}$ que também era diretor do DEEF (PIMENTEL, 1940). As atividades acadêmicas iniciaram com o Curso Normal de Educação Física, o primeiro a entrar em funcionamento no dia 6 de maio de 1940 (SILVEIRA, 1943). Os professores, alunos e funcionários pioneiros superaram dificuldades inerentes ao processo de fundação, tendo em vista o período de mudanças desencadeadas pelas ações políticas, culturais e educacionais no Estado Novo. Recuperar a memória destes personagens e das condições limitadas que impulsionaram o projeto de institucionalização da ESEF é uma forma, não apenas de homenageá-los, mas, principalmente, de permitir uma melhor compreensão de sua representação para a Educação Física e o esporte brasileiro.

\section{Dos Recursos Humanos: professores, alunos e funcionários}

O corpo docente pioneiro da ESEF era composto por profissionais do DEEF, que atuavam tanto nas disciplinas práticas como nas teóricas, a saber: capitão Olavo Amaro da Silveira (diretor do DEEF); segundo tenente Nelson Futuro Rocha (auxiliar da Divisão Técnica); primeiro tenente João Gomes Moreira Filho (chefe da Divisão de Ensino), Frederico Guilherme Gaelzer Neto ${ }^{7}$ (chefe da Divisão Administrativa); Leofrida Lima Bianchi (auxiliar da Divisão de Ensino); segundo tenente Flori Viterbo Barbosa (auxiliar da Divisão Técnica), primeiro tenente Max Herbert Hanke (chefe da Divisão Técnica); Zadir Martins (auxiliar da Divisão de Ensino); médico capitão Adhemar Pinto Torelly (chefe da Divisão Médica); médico capitão Raymundo Bezerra de Menezes (auxiliar da

6 O capitão Olavo Amaro da Silveira nasceu em 1906. Formou-se engenheiro geógrafo pela Escola Politécnica do Rio de Janeiro. Ingressou na Escola Militar do Rio de Janeiro e foi nomeado oficial do exército em 1930 e capitão em 1937. No Rio de Janeiro diplomou-se pela Escola de Educação Física do Exército (FRANCO; SILVA e SCHIDROWITZ, 1940, p. 627).

7 Frederico Guilherme Gaelzer morou nos Estados Unidos no período de 1919 a 1924, onde desenvolveu estudos sobre a Educação Física. Organizou cursos intensivos de Educação Física para professores de $1^{\circ}$ grau no Estado. É considerado o introdutor da recreação pública no Brasil (MAZO, 2003).

Movimento, Porto Alegre, v. 11, n. 1, p.143-167, janeiro/abril de 2005 
Divisão Técnica); médico capitão Ruy Gaspar Martins (auxiliar da Divisão Técnica); médico Poli Marcelino Espírito (fazia a ligação do Departamento Escolar de Saúde com o DEEF). Os professores que não tinham vínculo com o DEEF eram Lia Bastian Meyer Schmitz, Maria Moritz, sargento Waldir Calvet Echardt, primeiro tenente Mario Marques Ramos, ${ }^{8}$ médico Gabriel Pastor e médico Alfredo A. Hofmeister (PIMENTEL, 1940, p. 638-639).

No segundo ano de funcionamento do Curso Normal, em 1941, foram contratados novos professores para integrar o corpo docente da ESEF. Um número significativo de professoras passou a ministrar aulas, enquanto auxiliar de disciplinas: Antônia Seitz Petzhold; Zaida Marques Pallarés; Iula Maria O. Green; Lisarb Frota Coelho Vasconcellos; Elcy Dionéia Fernades da Silva; Olga Valéria Kroeff; Helena Dias Kurtz e Lêda Hecker. Os professores contratados ocuparam o cargo de titular nas disciplinas: segundo tenente Arthur Torriani; Rubem Mylins; médico Amadeu Faviero; primeiro tenente médico José Corrêa de Barros; médico capitão Ary da Costa Mariante; médico Hélio Barcelos Ferreira e Karl Black.

A partir de 1942, além do Curso Normal, a ESEF começou a oferecer novos cursos, tornando-se necessária a contratação de mais professores: Ary S. de Oliveira (Remo); médico Hassib Maluf (Higiene Aplicada e Metodologia) e Regina Soares de Amaro (Piano). Em 1943, várias professoras (Maria Isolina Leitão Krüger; Maria de Cesaro; Quintina Cândida Mara, Letícia Raquel Crocco Pacini e Suzana Loureiro Cony) ingressaram no corpo docente da ESEF, em razão do oferecimento da disciplina de Educação Física Geral também para uma turma feminina. As disciplinas de práti-

8 O tenente Mario Marques Ramos estudou no Centro Militar de Educação Física (fundado em 1922), instituição considerada o embrião da Escola de Educação Física do Exército. Iniciou sua carreira de professor de Educação Física em 1929, na cidade de Curitiba (Paraná), ministrando aulas no Ginásio Novo Atheneu, no Instituto Santa Maria e no Internato do Ginásio Paranaense. Foi nomeado catedrático po decreto especial do governo daquele Estado. Em 1932, inscreveu-se no registro de decreto especial do governo daquele Estado. Em 1932, inscreveu-se no registro de professores do Departamento Nacional de Ensino, sendo contratado pela Secretaria de Educação do Estado do Rio Grande do Sul. Foi transferido para Porto Alegre para atuar no Curso de Aperfeiçoamento da Escola Normal e também ministrou aulas no Ginásio Nossa Senhora das Dores (ANTUNES, 01/01/1937, p. 5). Em 1934 publicou a obra Educação Física pela Livraria do Globo de Porto Alegre. No período de 1937 a 1939 colaborou com a Revista do Globo, editada pela Livraria do Globo, redigindo e/ou traduzindo 28 artigos para a seção de Educação Física (MAZO, 2003).

9 Karl Black, filho do imigrante alemão Georg Black Sen, assumiu o cargo de professor de ginástica na SOGIPA em 1929, após retornar dos estudos na Alemanha. No período de 1940 a 1942 também atuou como técnico de atletismo feminino na SOGIPA (WIESER, 1990, p. 63).

Movimento, Porto Alegre, v. 11, n. 1, p.143-167, janeiro/abril de 2005 
cas esportivas já eram oferecidas separadamente para as turmas feminina e masculina, sendo ministradas as aulas, respectivamente, por professoras e professores.

O quadro de professores da ESEF nos primeiros anos era composto majoritariamente por médicos, militares e médico-militares. Dentre esses, havia professores oriundos da Escola de Educação Física do Exército - ESEFEx. ${ }^{10}$ O grupo com formação específica para o magistério era composto de professores e professoras. Alguns deles eram alunos egressos das primeiras turmas da ESEF, conforme registro nos Livros de Matrícula (Silveira, s/d; Pinto, s/d; Gaelzer, s/d (a); Gaelzer, s/d (b)).

Alguns ex-alunos da ESEF foram convidados para fazer parte do quadro docente da Escola, como foi o caso de Fredolino Taube, que ingressou em 1941 e formou-se no ano seguinte. Ele recebeu o convite do diretor da ESEF, Capitão Olavo Amaro da Silveira, para trabalhar como professor auxiliar da disciplina de Atletismo (conteúdos de arremessos e lançamentos), cujo professor titular era Rubem Emílio, responsável pela parte de corridas e saltos (NUNES, 2003). A escolha do professor Fredolino Taube estava relacionada ao seu ótimo desempenho acadêmico na ESEF e seu passado esportivo no atletismo, desde o ginásio."

Outro exemplo de ex-aluna da ESEF, que posteriormente veio a lecionar disciplinas na Escola, é da professora Odair Perugini de Castro. Ela foi presidente do Diretório Acadêmico da ESEF em 1943, no mesmo ano em que concluiu o Curso Superior em Educação Física, recebendo a distinção de "Melhor Companheiro/Espírito Coletivo" da ESEF (FREITAS, 2004). Odair de Castro, assim como Fredolino Taube, se destacou também enquanto atleta, mas na modalidade de voleibol, participando de campeonatos regionais e nacionais.

Além destes, vários outros ex-alunos das primeiras turmas da ESEF tinham vivências enquanto atleta tanto nas escolas quanto nos clubes. Apesar de que para ingressar nos cursos "não era necessário que os interessados já tenham demonstrado aptidões especiais para esse ou aquêle esporte" (REVISTA DO GLOBO, 1946,

10 Conforme Ferreira Neto (1999), a ESEFEx, inicialmente restrita aos militares, formou profissionais que foram atuar nas escolas de Educação Física.

11 O professor Fredolino Taube também trabalhou com Fisioterapia no Instituto Gaelzer e ministrou aulas de ginástica para cegos no Instituto Santa Luzia. Depois de formado atuou como técnico de atletismo feminino e masculino na SOGIPA até o início da década de 70, quando assumiu a direção da ESEF (NUNES, 2003).

Movimento, Porto Alegre, v. 11, n. 1, p.143-167, janeiro/abril de 2005 
p. 37), o processo seletivo para ingresso de alunos na ESEF era composto de exames físicos e intelectuais, além de ser exigido o certificado de Licença Ginasial ou de conclusão do Ciclo Fundamental do Curso Secundário. No caso dos candidatos ao Curso Normal também eram exigidas provas de avaliação da condição física, dentre as quais a capacidade de nadar a distância de 25 metros. Para viabilizar a participação dos candidatos na prova de natação, a ESEF oferecia anualmente, durante todo o mês de fevereiro, um curso de preparação para aqueles que não sabiam nadar.

Embora Pimentel (1940, p. 638-39) tenha referido que o grupo de alunos da primeira turma do Curso Normal era constituído por 118 alunos, sendo 93 do sexo feminino e 25 do sexo masculino, o levantamento realizado na documentação do Centro de Memória do Esporte da ESEF constatou que a turma era composta de 124 alunos, confirmando a informação de Brauner (1993). A maioria dos alunos da primeira turma, 119 alunos num total de 124, era oriunda do Estado do Rio Grande do Sul. Destes alunos, 36 eram provenientes da cidade de Porto Alegre e 83 de outros municípios (SILVEIRA, s/d). Muitos alunos já atuavam enquanto professores nas escolas estaduais de Porto Alegre (PIMENTEL, 1940). Cabe salientar que apenas cinco alunos tinham outra naturalidade: Corina Pereira da Costa do Distrito Federal (Rio de Janeiro); Alba Ferreira de Souza de São Salvador (Bahia), Orestes Klein de Santo Amaro, São Paulo; Livio Amaury Rocco de Entre Rios, Concórdia (Argentina) e Karl Black da Raviera, Munich (Alemanha) (SILVEIRA, s/d).

Conforme o entrevistado médico Henrique Licht, ${ }^{12}$ a ESEF formou lideranças desportivas no Estado do Rio Grande do Sul: "da ESEF saíram muitos líderes, especialmente, o Selviro ${ }^{13}$ e muitos outros, né, o número é muito grande". Conclui seu depoimento afirmando que "a coisa mais importante para o esporte gaúcho foi a criação da Escola de Educação Física". Carlos Alberto Garcia, ex-aluno da ESEF, também salientou a formação profissional oferecida pela ESEF: "Na época da conclusão do meu curso de Educação Física, ser diplomado pela UFRGS era garantia de trabalho. Avalio isso pelos meus colegas da época que hoje ocupam cargos de destaque nas mais variadas áreas, o que prova a importância

12 Formou-se na Faculdade de Medicina da Universidade do Rio Grande do Sul em 1946. Fez o curso de Medicina da Educação Física e do Desporto na ESEF em 1950 onde trabalhou como médico voluntário durante um ano. Atuou como professor convidado da ESEF no período 1967-1968 (MAZO, 2000).

13 Selviro Rodrigues da Silva foi o primeiro diretor da Faculdade de Educação Física do Instituto Porto Alegrense (IPA), fundada em 1971.

Movimento, Porto Alegre, v. 11, n. 1, p.143-167, janeiro/abril de 2005 
da UFRGS em nossas vidas" (OLIVEIRA e LICHT, 2004, p. 189). Cabe destacar que as lideranças não emergiram apenas do quadro docente e discente da ESEF, mas também do grupo de funcionários. Alguns funcionários ocuparam, posteriormente, o cargo de professores da instituição.

Desde a fundação até o ano de 1942, os funcionários que atuavam na ESEF eram vinculados ao DEEF. Foi encontrado na documentação consultada registros de funcionários da Secretaria da ESEF a partir de 1943: Marina Martins de Souza - secretária; Lisarb Frota Coelho - oficial administrativo (nos anos de 1941 e 1942 atuou como professora auxiliar de Voleibol); Francisco Damado Guincosi - oficial administrativo; e Nery Ferreira - datilógrafo. Os funcionários da Seção Didática eram: Elisa H. Dora Cibelli - adjunto; Nilza Endres - oficial administrativo; Souvarine Silva - datilógrafo; Deodoro Passos Paradeda - mimeografista e Enio Ribeiro servente. Além desta seção, foi organizada a Seção de Ensino, com a contratação de funcionários para atender às necessidades do curso em razão do oferecimento de novas disciplinas.

\section{Das Disciplinas}

As disciplinas do Curso Normal, primeiro curso oferecido pela ESEF, foram divididas em práticas e teóricas. As disciplinas práticas eram compostas pelos seguintes modalidades: Desportos Aquáticos (natação, remo, canoagem e pólo aquático, sendo este último a partir de 1941); Desportos Terrestres Individuais (atletismo); Desportos Terrestres Coletivos (voleibol, basquete, futebol); Desportos de Ataque e Defesa; Ginástica de Aparelhos e Pesos e Halteres; Ginástica Rítmica; Canto Coral; e Educação Física Geral. Já as disciplinas teóricas eram as seguintes: Anatomia e Fisiologia Humanas, Biometria, Cinesiologia, Fisioterapia, Higiene Aplicada, História e Organização da Educação Física e dos Desportos, Socorros de Urgência, Metodologia da Educação Física, Psicologia Aplicada (a partir de 1941), Metodologia (a partir de 1941), Traumatologia Desportiva (a partir de 1941), Fisiologia Aplicada (a partir de 1941) (SILVEIRA, 1943; PIMENTEL, 1940, p. 638-39). As aulas teóricas eram ministradas em conjunto, enquanto que as aulas práticas eram em turmas separadas por sexo. Tanto para a turma feminina quanto para a masculina, as aulas práticas de natação eram realizadas somente no verão (princípio de outono e no fim da primavera). Os exames finais da disciplina de natação eram considerados "puxados" pelas alunas, que após sorteio do tema da aula, eram subme-

Movimento, Porto Alegre, v. 11, n. 1, p.143-167, janeiro/abril de 2005 
tidas a uma banca examinadora composta por três professores (REVISTA DO GLOBO, 1946).

Além do Curso Normal, ${ }^{14}$ outros cursos foram oferecidos pela ESEF, após a parceria com o Esporte Clube Cruzeiro em 08/01/ 1942: Curso de Medicina de Educação Física e Esportes (duração de um ano); Curso de Técnica Desportiva (duração de um ano); Curso de Treinamento e Massagem (duração de um ano) e Curso Superior de Educação Física (duração de dois anos a partir de 1947). A entrevistada Ilse Süffer, ex-atleta, que realizou o Curso Superior de Educação Física na ESEF no período de 1943 a 1944, declarou que o objetivo deste curso "era a preparação de professores para atuar nas associações esportivas". Para todos os cursos da ESEF eram aceitos candidatos de ambos os sexos, entretanto, havia algumas diferenças entre as disciplinas oferecidas para as turmas femininas e masculinas. As turmas masculinas tinham um número superior de práticas esportivas em meados da década de 40: “Os rapazes da escola praticam tênis, ginástica acrobática e de aparelhos, esgrima, remo, natação, boxe, jiu-jitsu, futebol, basquetebol, voleibol, etc." (REVISTA DO GLOBO, 1946, p. 37).

As aulas das disciplinas práticas e teóricas não eram ministradas no mesmo local, tendo em vista que a ESEF não tinha instalações próprias. Devido a esta situação, até o início da década de 60 , a Escola enfrentou vários problemas de infra-estrutura.

\section{Da Infra-Estrutura}

A ESEF foi fundada sem ter instalações próprias para realizar suas atividades. Para viabilizar o início das atividades acadêmicas da Escola, o DEEF instalou a secretaria administrativa em uma sala alugada, localizada na Avenida João Pessoa, n. 1003. Esta secretaria permaneceu neste local durante a gestão dos três primeiros diretores: capitão Olavo Amaro da Silveira (1940-1944), Jaguaré Teixeira (1944-1945) e Jacintho Francisco Targa - nomeado pela Portaria n. 232 de 05/10/1945 (PIMENTAL, 1940).

Para a realização das aulas práticas orientadas para os diferentes esportes, o DEEF estabeleceu parcerias com algumas associações esportivas: Natação no Yatch Club e no Grêmio Náutico União;

14 O Curso Normal foi oferecido enquanto a ESEF estava vinculada ao DEEF, sendo extinto quando a Escola foi federalizada (TARGA apud PICCOLI, 1994, p. 10).

15 Após este período na direção da ESEF retornou as suas atribuições militares (MAZO, 2003).

Movimento, Porto Alegre, v. 11, n. 1, p.143-167, janeiro/abril de 2005 
Remo no Club de Regatas Cannotieri Duca degli Abruzzi; Canoagem no Lago do Parque Farroupilha; Atletismo, Voleibol, Basquete e Futebol no Estádio General Ramiro Souto; Ginástica Rítmica no salão de ginástica do Ginásio Bom Conselho; Canto Coral no Grupo Escolar Paula Soares (PIMENTEL, 1940, p. 638-39; BRAUNER, 1993). As aulas das disciplinas teóricas, contemplando os conteúdos da área de Ciências da Saúde, eram realizadas no Instituto de Química da Universidade de Porto Alegre.

No início da década de 50, sob a direção do capitão Jacintho Targa (1945-1953), ocorreram as primeiras tentativas de construção de instalações próprias da Escola. Algumas possibilidades foram cogitadas. O Reitor Alexandre Rosa sugeriu a construção de instalações na Cidade Universitária da Universidade do Rio Grande do Sul (URGS), ${ }^{16}$ que seriam financiadas pelo Estado do Rio Grande do Sul. Inicialmente, o objetivo era a construção de um Estádio Universitário junto ao Hospital de Clínicas da URGS (SILVEIRA, 1943). Este fato não se concretizou, provavelmente, porque o Estado não tinha recursos, e a ESEF permaneceu sediada no Esporte Clube Cruzeiro, sob a tutela do Estado. Caso esta alternativa tivesse se consolidado, a ESEF já teria sido incorporada pela URGS na década de 50. Também foi discutida a possibilidade de aquisição das instalações do Esporte Clube Cruzeiro para constituir-se na sede própria da ESEF, pois era um espaço já utilizado desde o início das atividades. Outra alternativa que surgiu foi instalar a sede da ESEF no prédio de uma escola que estava sendo construída na Rua Botafogo, próxima do estuário do Guaíba, facilitando a prática de desportos náuticos (CARDOSO, 1965).

Tendo em vista que estas tentativas de mudanças fracassaram, a ESEF permaneceu desenvolvendo a maioria das suas atividades no Estádio do Esporte Clube Cruzeiro até 1956, quando passou a utilizar as instalações da Associação Cristã de Moços ACM (BRAUNER, 1993). A ACM de Porto Alegre, fundada em 1901 é considerada uma referência no desenvolvimento da Educação Física: "A educação física se desenvolveu graças a Associação Cristã de Moços de Georg Black, pioneiro deste genero de trabalho em Pôrto Alegre, das praças de recreio e jogos da prefeitura municipal e trabalhos nos estabelecimentos do ensino primário e secundário" (FRANCO; SILVA e SCHIDROWITZ, 1940, p. 637).

16 Universidade de Porto Alegre, que passa a ser denominada Universidade do Rio Grande do Sul (URGS), conforme Lei Federal n. 1254 de 4/12/1950.

Movimento, Porto Alegre, v. 11, n. 1, p.143-167, janeiro/abril de 2005 
A mudança da ESEF para uma sede própria no Bairro Jardim Botânico, de acordo com Gaelzer (s/d-b), ocorreu somente em 1963, sob a direção do médico Ruy Gaspar Martins (1959-1964). O terreno para a construção das futuras instalações da ESEF foi doado pelo Estado do Rio Grande do Sul na gestão do governador Ildo Meneghetti. As novas instalações construídas eram precárias e mantiveram-se assim durante a gestão dos três diretores interinos: o médico Arno Tschiedel, Coronel Jacintho Francisco Targa e médico Ney Serres Rodrigues. Os diretores assumiram suas funções em 1964, ano em que os militares impuseram um novo regime político no país. No ano seguinte foi indicado um novo diretor: o médico Hélio Barcelos Ferreira (1965-1970). Neste período, segundo depoimento do médico Eduardo De Rose, "17 "a ESEF era uma Escola pobre; não tinha material nenhum". A ESEF, apesar de contar com uma grande área física, não possuía espaços adequados para as práticas esportivas e nem salas de aula suficientes para as atividades teóricas. Os problemas de infra-estrutura, inclusive, dificultavam a promoção de eventos que a Escola procurava realizar para afirmar-se no cenário esportivo e educacional do Estado do Rio Grande do Sul.

\section{Dos eventos}

Em abril de 1941, quase um ano após o início das atividades da ESEF, o DEEF promoveu a solenidade de abertura do Curso Normal de Educação Física no Estádio General Ramiro Souto, com a presença de várias autoridades locais. Neste ato público, as alunas normalistas da ESEF desfilaram, demonstrando, assim, o prestígio da Escola já nos primeiros anos de funcionamento (REVISTA DO GLOBO, 1941b). Ainda no mês de abril, a ESEF recebeu a visita do major João Barbosa Leite, diretor da Divisão de Educação Física do Ministério da Educação e Saúde, fato que concedeu à ESEF mais visibilidade nacional

O primeiro evento promovido pela ESEF foi a cerimônia de Colação de Grau da primeira turma de alunos que ingressaram no Curso Normal. Esta solenidade foi realizada no Teatro São Pedro em 31/01/1941 (REVISTA DO GLOBO, 1941a). Cabe ressaltar que o fato de esta formatura ter sido realizada neste teatro traduz a impor-

17 Médico graduado pela Faculdade Federal Fundação de Ciências Médicas (Porto Alegre) em 1966. Concluiu o Curso em Medicina do Esporte na ESEF em 1968 Alegre) Começou a ministrar aulas nas disciplinas de Socorros de Urgência e Fisiologia do Exercício na ESEF em 1969 (MAZO, 2000).

Movimento, Porto Alegre, v. 11, n. 1, p.143-167, janeiro/abril de 2005 
tância do evento. Após esta formatura no início do ano, todas as demais ocorreram no mês de dezembro sempre no Teatro São Pedro. Somente em dezembro de 1947, a Colação de Grau foi transferida para a sala Ruy Barbosa do Esporte Clube Cruzeiro, onde eram realizadas várias aulas práticas. A partir de então, começou uma alternância de lugares: Teatro São Pedro (1948); Esporte Clube Cruzeiro (1949; 1951) e Pontifícia Universidade Católica do Rio Grande do Sul (1950; 1952). A dificuldade de um local fixo para as formaturas acompanhou a ESEF até sua federalização.

A participação da ESEF em festividades cívicas na Semana da Pátria foi constatada desde sua fundação: Parada da Mocidade (05/9/1941, 06/9/1942, 05/9/1943, 02/9/1944, 9/1945, 02/9/1951); Sessão Cívica em Homenagem a Memória de Duque de Caxias em 26/8/1942; Demonstração de Educação Física no Campo de Pólo atual Redenção (02/9/1942, 03/9/1943, 17/9/1944, 9/1945); Hora da Pátria (07/9/1943, 07/9/1951); Homenagem ao General Osório na Praça General Osório (25/9/1942); Comemoração de mais um Aniversário do Estado Novo (10/10/1943); Saudação ao Presidente Getúlio Vargas (13/10/1943); Corrida do Fogo Simbólico (31/8/1944, 01/9/1947, 01/9/1951); Participação na Parada Militar (07/9/1944); Festa Esportiva da Semana da Pátria (01/9/1946); Hasteada a Bandeira Nacional (01/9/1949) (SILVEIRA, 1943; PIMENTEL, 1940; REVISTA DO GLOBO, 1942). Em algumas comemorações, os alunos cantavam o hino da Escola, o qual enfatizava a importância da prática desportiva para a juventude, visando à construção da nação brasileira. A letra é de Paulo Antônio Moritz e a música de Natho Hehn:

Mocidade do Brasil avante! Cultivemos a beleza do corpo; melhorando a nossa raça; à pátria dedicando este ideal; que é força e beleza sem par (bis ); assim cantando, marchemos sem temor; todos nós somos da pátria; uma esperança; e cultivemos com fé e ardor; nossa sagrada missão.

A entrevistada Liselot Barth, ex-atleta, formada pela ESEF, emocionou-se ao comentar sobre sua participação no desfile da Semana da Pátria em 1941: "aquilo era muito bonito. A ESEF organizou um bailado no campo onde atualmente é... a Faculdade de Odontologia e o Hospital de Clínicas. Era um campo grande; então, algumas moças da Educação Física e os rapazes da Escola de Cadetes fizeram um bailado, as moças de gaúchas e os rapazes também". Érika Renner de Araújo, relatou que na época em que estudou na ESEF participou de atividades de dança, além de ser atleta da SOGIPA na equipe de atletismo feminino.

Movimento, Porto Alegre, v. 11, n. 1, p.143-167, janeiro/abril de 2005 
Além dos alunos foi destacada a presença de alguns professores da ESEF à frente destas atividades cívicas. O professor Frederico Guilherme Gaelzer era o responsável pela organização da participação dos alunos nos desfiles da Semana da Pátria: "nesta parte do desfile, Gaelzer sempre o grande líder e depois já com os seus alunos" (depoimento de Henrique Licht). Os alunos, geralmente desfilavam uniformizados vestindo "uma calça e camiseta na cor azul marinho com o distintivo da ESEF. Já as alunas vestiam camiseta e saia nas cerimônias cívicas" (depoimento da ex-aluna Ida Almaleh). A "brilhante" participação da ESEF nos eventos cívicos e esportivos foi destacada nas páginas da Revista do Globo nas décadas de 40, 50 e 60.

Em 1965 foi publicada uma reportagem sobre o jubileu de prata da ESEF (1940-1965), ilustrada com imagens desta festa realizada nas instalações próprias da ESEF no Bairro Jardim Botânico. O evento comemorativo reuniu professores, alunos, funcionários, autoridades municipais e estaduais, além da comunidade em geral. Nesta reportagem, foi destacado o trabalho desenvolvido pela ESEF, que ao longo dos seus 25 anos formou um número expressivo de profissionais: 393 professores (licenciados), 389 professores normalistas, 35 médicos especializados, 15 massagistas, 28 técnicos esportivos, 29 instrutores de Educação Física para a Brigada Militar, 10 recreacionistas e 44 professores especialistas em Ginástica Rítmica e Danças (CARDOSO, 1965, p. 43). Esta diversidade na formação profissional proporcionada pela ESEF, certamente contribuiu para ampliar a compreensão acerca do campo de atuação do profissional de Educação Física.

\section{Considerações Finais}

A reconstituição da memória da Escola de Educação Física (ESEF) no período em que estava sob a tutela do Estado (19401969), objetivo central deste estudo, foi permeada pelos seguintes eixos norteadores: perfil de professores, alunos e funcionários; condições das instalações onde eram realizadas as aulas, e a caracterização da participação da ESEF em eventos cívicos e esportivos. Para tanto, buscou-se, inicialmente, contextualizar as ações políticas, culturais e educacionais do Estado Novo (1937-1945) para analisar a fundação da ESEF. A seguir, procurou-se traçar os caminhos percorridos pela ESEF desde a fundação até a sua incorporação à Universidade Federal do Rio Grande do Sul.

Movimento, Porto Alegre, v. 11, n. 1, p.143-167, janeiro/abril de 2005 
A fundação da ESEF constituiu-se num marco referencial na formação profissional em Educação Física no Estado do Rio Grande do Sul e, inclusive, no Brasil. Sendo a primeira instituição formadora de professores de Educação Física no Estado, interferiu, significativamente, nos rumos das atividades físicas e esportivas desenvolvidas nas escolas, clubes e praças do Rio Grande do Sul. A ESEF também foi responsável pela formação dos professores pioneiros nas instituições de ensino superior, que foram fundadas a partir do início da década de 70 no Estado.

A presença expressiva de militares e médicos no corpo docente pioneiro da ESEF demonstra que predominava a influência militar e médico-higienista no perfil dos professores e, conseqüentemente, na formação dos alunos. O estudo de Ghiraldelli Jr. (1991) destacou a influência militar e médica na Educação Física brasileira, especialmente nas décadas de 30 e 40 . A influência médica está expressa na tendência da "Educação Física Higienista", a qual estava voltada tanto para a saúde individual quanto para a saúde coletiva, através da educação. Já a influência dos militares, denominada pelo autor (1991) de "Educação Física Militarista" pregava padrões de comportamento disciplinar próprios do regime militar.

Ferreira Neto (1999, p. 55) afirmou que todos os cursos de Educação Física fundados após a criação da Escola de Educação Física do Exército seguem o seu "padrão", o qual tem sua matriz na "Escola de Joinville-Le-Pont". Ao se comparar as disciplinas do primeiro currículo da ESEF com as oferecidas no Curso de Instrutores da Escola de Educação Física do Exército, pode-se perceber a estreita relação referida por Ferreira Neto (1999).

Castellani Filho (1983) realizou uma análise crítica acerca da influência da instituição médica na Educação Física brasileira, enfatizando que o pensamento dos médicos gerou uma concepção reducionista da Educação Física aos aspectos biológicos. O número significativo de médicos entre os primeiros professores sugere a busca de uma formação do professor de Educação Física voltada para a manutenção da saúde física e biológica. Isto pode ser observado na composição da primeira grade curricular do Curso Normal, que oferecia as seguintes disciplinas teóricas: Anatomia e Fisiologia Humanas, Biometria, Cinesiologia, Fisioterapia, Higiene Aplicada, Socorros de Urgência, Traumatologia Desportiva e Fisiologia Aplicada. O médico Belmar Andrade ${ }^{18}$ comenta a influência da institui-

18 Médico graduado pela Faculdade Católica de Medicina de Porto Alegre em 1969. Realizou o Curso de Medicina do Esporte na ESEF/UFRGS em 1970 (MAZO, 2000).

Movimento, Porto Alegre, v. 11, n. 1, p.143-167, janeiro/abril de 2005 
ção médica na ESEF: “A Escola teve inúmeros médicos como diretores até que tivesse o corpo de professores de Educação Física; porque a Medicina se desenvolveu antes da Educação Física, como uma ciência bem estruturada e com profissionais que procuravam se inteirar com a pesquisa. Então é o que aconteceu com a Escola de Educação Física, que teve uma série de médicos como diretores até que os professores assumissem". Em via de regra, enquanto os médicos tratavam das disciplinas teóricas, os militares eram responsáveis pelas disciplinas de práticas esportivas.

Este contexto, no princípio, atribuiu uma identidade predominantemente masculina ao corpo docente da ESEF. A contratação de professoras ocorreu somente em razão da obrigatoriedade do curso em oferecer disciplinas para as turmas femininas, como por exemplo, a Ginástica Rítmica. A partir de então, se percebeu a necessidade de oferecer as práticas esportivas também para a turma feminina e, por esta razão, novas professoras foram contratadas para atender este grupo. O ingresso de mulheres no corpo docente pioneiro da ESEF foi concedido pela própria legislação e, assim, as professoras foram conquistando um espaço profissional identificado historicamente com os professores.

A ampliação do quadro docente permitiu o oferecimento de novos cursos e a conseqüente ampliação do número de vagas para o ingresso de alunos. Esta situação trouxe alguns problemas para a direção da ESEF, que não tinha instalações próprias para as aulas. A realização das atividades acadêmicas dependia da autorização das associações esportivas para o uso de algumas de suas instalações e equipamentos. Estas associações cediam seus espaços para a ESEF sem custos adicionais, pois sabiam que a Escola não possuía recursos suficientes.

Uma das principais parcerias constituída pela ESEF foi com o Esporte Clube Cruzeiro, que permitia a utilização da maioria de suas instalações. Outra importante parceria ocorreu com a Associação Cristã de Moços (ACM), através da influência do professor Frederico Guilherme Gaelzer, no período em que assumiu a direção da ESEF (1955-1959). O professor Gaelzer já conhecia o trabalho de Educação Física desenvolvido pelas ACMs nos Estados Unidos, onde realizou parte de sua formação acadêmica. Ele também acompanhava as atividades de Educação Física promovidas pela ACM de Porto Alegre (fundada em 1901).

Até o início da década de 60, a ESEF continuou dependendo totalmente das associações esportivas para a manutenção de suas atividades. Somente em 1963 conquistou um espaço próprio, ao

Movimento, Porto Alegre, v. 11, n. 1, p.143-167, janeiro/abril de 2005 
receber a doação de um terreno do governo do Estado para a construção das futuras instalações. Tendo em vista a escassez de recursos financeiros, as primeiras instalações eram precárias. Tais condições de infra-estrutura não se constituíram em obstáculo às atividades didático-pedagógicas da ESEF.

Cabe também ressaltar a importância da participação da ESEF em eventos cívicos e esportivos para impulsionar seu projeto acadêmico. A representatividade da ESEF nas cerimônias da Semana da Pátria era uma demonstração do seu engajamento nas idéias políticas, culturais e educacionais do Estado Novo. A ESEF, seguindo orientações de caráter higienista, militarista e eugênico, conforme discurso do seu primeiro diretor, capitão Olavo Amaro da Silveira, também visava uma educação cívica, através da Educação Física.

Por fim, vale registrar a relevância das ações dos professores e professoras, dos funcionários e funcionárias, dos alunos e alunas, assim como da própria comunidade porto-alegrense, que trilharam os caminhos da Escola Superior de Educação Física num período em que não havia instalações e nem recursos materiais próprios. Impulsionados por idéias revolucionárias no âmbito da saúde e da educação foram em busca de parcerias com as associações esportivas, até então, as grandes responsáveis pelo desenvolvimento da Educação Física e do esporte no Estado. Assim, a ESEF atravessou três décadas construindo conhecimento, atendendo a comunidade e, principalmente, fomentando uma cultura física e esportiva de referência nacional.

Movimento, Porto Alegre, v. 11, n. 1, p.143-167, janeiro/abril de 2005 
Memories of the College of Physical Education of the Federal University of Rio Grande do Sul (ESEF/ UFRGS): an study since the foundation until the federalization (1940-1969)

Abstract: The College of Physical Education - ESEF/ UFRGS was the first school to prepare teachers of Physical Education to be established in the state of Rio Grande do Sul during the period known as Estado Novo (1937-1945). The objective of this study is to reconstruct the history of the College of Physical Education ESEF/ UFRGS from its inauguration until its federalization (19401969). For this study we first identified faculty members, students and staff. We also give a detailed description of the conditions they had to work in, and the buildings in which they had to teach classes. In order to accomplish this historical background, extensive research was made into historical documents, magazines, and journals, as well as interviews with former professors and students. The study concludes that political, cultural and educational actions taken during the Estado Novo in 1940 were favorable to the College of Physical Education - ESEF/ UFRGS. However, when the College of Physical Education - ESEF/UFRGS was federalized under the state government of Rio Grande do Sul until 1969 the school suffered in that it was more restricted.

Keywords: memories, ESEF/UFRGS, foundation, state government. 


\begin{abstract}
Memoria de la Escola Superior de Educação Física de la Universidade Federal do Rio Grande do Sul (ESEF/UFRGS): un estudio del periodo de su fundación hasta la federación (1940-1969)

Resumen: La Escola de Educação Física-ESEF/UFRGS

fue la primera institución formadora de profesores de Educación Física fundada en el Rio Grande do Sul durante el Estado Novo (1937-1945). El proyecto de investigación tiene como meta reconstituir la memoria de la ESEF/UFRGS, desde su fundación hasta su federación (1940-1969), intentando identificar los primeros profesores, estudiantes y funcionarios y registrar las condiciones de los equipos y de las instalaciones donde eran realizadas las clases. Por lo tanto, fueron consultados documentos institucionales, revistas y periódicos, así como fueron colectados testimonios orales de ex profesores y estudiantes. Las acciones políticas, culturales y educacionales desencadenadas en el Estado Novo contemplaron la fundación de la ESEF/UFRGS en 1940 Mientras la ESEF/UFRGS estuvo bajo la tutela del gobierno de la provincia del Rio Grande do Sul (hasta 1969) sus condiciones de funcionamiento eran limitadas, sobre todo por el hecho de que las actividades no eran realizadas en instalaciones propias.

Palabras-clave: memoria, ESEF/UFRGS, fundación, administración provincial.
\end{abstract}

\title{
Referências
}

ANTUNES, P. Educação Physica. Jornal Correio do Povo, 01/01/1937, p. 5.

AVANCINI, E. O Canto orfeônico Escolar e a formação da Identidade Nacional no Brasil (1937-1961). Tese de Doutorado. PPGH/UFRGS, Porto Alegre, 2000.

BERCITO, S. Ser forte para fazer a nação forte: a educação física no Brasil, 1932-1945. Dissertação de Mestrado. FFLCH/USP. São Paulo, 1996.

BETTI, M. Educação Física e Sociedade. São Paulo: Editora Movimento, 1991.

BRAUNER, Vera. La Formación del profesorado de educación física en la UFGRS, Porto Alegre (Brasil). Tendencias Teóricas. Tese de Doutorado. Universitat de Barcelona. 1993.

CARDOSO, R. Alunos da ESEF promovem festa de ritmo, graça e agilidade. Revista do Globo, n. 901 de 19/6/1965, p. 42-43. In: MAZO, J. O Esporte e a Educação Física na Revista do Globo: Catálogo (1929-1967). Porto Alegre: FEFID/ PUCRS; ESEF/UFRGS, 2004 (CD-ROM).

Movimento, Porto Alegre, v. 11, n. 1, p.143-167, janeiro/abril de 2005 
CANTARINO, M. A Educação Física no Brasil. In: Ueberhorst, H. (org.). Geschichte der Leibesübungen. Berlin: Bartes \& Wernitz, 1989, p. 889-911.

CARONE, E. O Estado Novo (1937-45). São Paulo: DIFEL, 1976.

CASTELLANI FILHO, L. A (des) caracterização profissional filosófica da Educação Física. Revista Brasileira de Ciências do Esporte. São Paulo, v. 4, n. 3, 1983, p. 95-101.

CASTELLANI FILHO, L. Educação Física no Brasil: a história que não se conta. Campinas: Papirus, 1989.

DACOSTA L. Diagnóstico de Educação Física/Desportos no Brasil. Rio de Janeiro: MEC/FENAME, 1971.

FARIA JÚNIOR, A. Professor de Educação Física, Licenciado Generalista. In: OLIVEIRA, V. (org.). Fundamentos Pedagógicos Educação Física. Rio de Janeiro: Ao Livro Técnico, 1987, p. 15-33.

FERREIRA NETO, A. A Pedagogia no Exército e na Escola: a educação física brasileira (1880-1950). Aracruz, ES: FACHA, 1999.

FIORI, N. Homogeneidade cultural brasileira: estratégias governamentais sob o Estado Novo. In: Adorno, S. (org.). A sociologia entre a modernidade e a contemporaneidade. Porto Alegre: Editora da Universidade/UFRGS, 1995, p. 209-226.

FRANCO, A.; SILVA, M. e SCHIDROWITZ, J. (orgs.). Porto Alegre: biografia duma cidade. Livro Comemorativo do Bicentenário da Fundação da Cidade. Porto Alegre: Tipografia do Centro, 1940.

FREITAS, A. Perfil Odair Perugini de Castro: em busca da vida boa. Jornal da Universidade UFRGS, Ano VI, n. 68, Janeiro/Fevereiro de 2004, p. 12.

GAELZER, F. Livro de Matrícula 1958-1965 (1ac chamada). Secretaria ESEF, s/d (a).

GAELZER, F. Livro de Matrícula 1965-1971 (2ª chamada). Secretaria ESEF, s/d (b).

GHIRALDELLI JÚNIOR, P. Educação Física Progressista: A Pedagogia Crítico-Social dos conteúdos e a Educação Física brasileira. $3^{\mathrm{a}}$ ed. São Paulo: Loyola, 1991.

GUEDES, P. \& SANGUINETTI, Y. (orgs.). UFRGS: Identidade e Memórias - 19341994. Porto Alegre: Editora da Universidade/UFRGS, 1994.

GUTIERREZ, W. Diagnóstico das Escolas de Educação Física do Estado do Rio Grande do Sul. Dissertação de Mestrado. UFRGS. Porto Alegre, 1976.

LIMA, O. Amanuense Municipal. Intendência Municipal de Porto Alegre, 1909

LEVINE, R. O Regime de Vargas: os anos críticos - 1934-1938. Rio de Janeiro: Nova Fronteira, 1980.

Movimento, Porto Alegre, v. 11, n. 1, p.143-167, janeiro/abril de 2005 
MAZO, J. O Centro de Educação Física da Universidade Federal de Santa Maria: percorrendo os caminhos de sua criação. Dissertação de Mestrado. CEFD/UFSM, Santa Maria, 1993.

MAZO, J. História do Centro de Educação Física e Desportos da Universidade Federal de Santa Maria. Santa Maria: UFSM; CEFD, 1997.

MAZO, J. Laboratório de pesquisa do Exercício da ESEF/UFRGS: apontamentos para uma história dos seus 25 anos. Revista Movimento. Universidade Federal do Rio Grande do Sul. Escola de Educação Física. Edição Especial, Ano VI, 2000.

A Emergência e a Expansão do Associativismo Desportivo em Porto Alegre - Brasil (1867-1945): espaço de representações da identidade cultural teuto-brasileira. Dissertação de Doutorado. Universidade do Porto. Portugal, 2003.

MELO, V. Escola Nacional de Educação Física e Desportos - uma possível história. Dissertação de Mestrado. Faculdade de Educação Física/UNICAMP, Campinas, 1996.

NEGRINE, A (org.). Perfil do Curso de Mestrado em Ciências do Movimento Humano desde sua implantação 1989-1995. Universidade Federal do Rio Grande do Sul. Escola de Educação Física. Porto Alegre, maio de 1996.

NUNES, C. O processo de federalização da ESEF/UFRGS na perspectiva dos professores: um estudo de caso. Trabalho de Conclusão de Curso. ESEF/ UFRGS, 2003.

OLIVEIRA, C. \& LICHT, F. (orgs.). UFRGS 70 anos. Porto Alegre: Gráfica e Editora Comunicação Impressa, 2004.

ORTIZ, R. Cultura Brasileira e Identidade Nacional. São Paulo: Brasiliense, 1994.

PESAVENTO, S. Um dia, um outro tempo. In: OLIVEIRA, C. \& LICHT, F. (orgs.). UFRGS 70 anos. Porto Alegre: Gráfica e Editora Comunicação Impressa, 2004, p. 9-75.

PICOLLI, J. A Educação Física na escola pública do Rio Grande do Sul: antecedentes históricos (1857-1984). Pelotas: Editora da UFPEL, 1994.

PIMENTEL, F. Álbum do Bicentenário de Porto Alegre. Porto Alegre, 1940.

PINTO, D. Livro de Matrícula 1944-1957. Secretaria da Escola de Educação Física, s/d.

Revista do Globo. Formatura da ESEF, n. 290, 22/02/1941, p. 44. In: MAZO, J. O Esporte e a Educação Física na Revista do Globo: Catálogo (1929-1967). Porto Alegre: FEFID/PUCRS; ESEF/UFRGS, 2004 (CD-ROM).

Revista do Globo. Abertura dos Cursos Superiores de Educação Física, n. 294, 26/ 4/1941, p. 27. In: MAZO, J. O Esporte e a Educação Física na Revista do Globo: Catálogo (1929-1967). Porto Alegre: FEFID/PUCRS; ESEF/UFRGS, 2004 (CD-ROM).

Movimento, Porto Alegre, v. 11, n. 1, p.143-167, janeiro/abril de 2005 
Revista do Globo. A Mocidade Brasileira vibra de entusiasmo durante a Semana da Pátria, n. 326, 12/9/1942, p. 25-7. In: MAZO, J. O Esporte e a Educação Física na Revista do Globo: Catálogo (1929-1967). Porto Alegre: FEFID/PUCRS; ESEF/UFRGS, 2004 (CD-ROM).

Revista do Globo. Escola de Sereias, n. 425, 21/12/1946, p. 35-37. In: MAZO, J. O Esporte e a Educação Física na Revista do Globo: Catálogo (1929-1967). Porto Alegre: FEFID/PUCRS; ESEF/UFRGS, 2004 (CD-ROM).

RIO GRANDE DO SUL. Constituições do Estado do Rio Grande do Sul. Porto Alegre: Instituto de Informática Jurídica da Procuradoria-Geral do Estado, v. $1,1990$.

SCHWARTZMAN, S.; BOMENY, H. e COSTA, V. Tempos de Capanema. Rio de Janeiro/São Paulo: Editora Paz e Terra/EDUSP, 1984.

SILVEIRA, O. Histórico da ESEF. Secretaria da ESEF, outubro de 1943.

SILVEIRA, O. Livro de Matrícula 1940-1943. Secretaria da ESEF, s/d.

WASSERMAN, C. A questão nacional na América Latina no começo do século XX: México, Argentina, Brasil. Tese de Doutorado. PPGH/PUCRJ. Rio de Janeiro, 1998.

\section{Entrevistas}

Belmar José Ferreira de Andrade. Entrevista realizada em 23/4/1997. Eduardo Henrique De Rose. Entrevista realizada em 22/8/1997.

Érika Renner de Araújo. Entrevista realizada em 12/8/2002.

Henrique Licht. Entrevista realizada em 19/8/2002.

Ida Maria Almaleh. Entrevista concedida em 09/11/2004.

Ilse Süffert Doormann. Entrevista realizada em 16/8/2002.

Liseloth Barth. Entrevista realizada em 30/8/2002.

Recebido em: 20/02/2005

Aprovado em: 15/3/2005

Janice Zarpellon Mazo Av. Lucas de Oliveira, 2507/402 Bairro Petrópolis Porto Alegre/RS CEP: 90.460-001

balbijan@terra.com.br

Movimento, Porto Alegre, v. 11, n. 1, p.143-167, janeiro/abril de 2005 